resources. During the past fifteen years, six institutes have been established which are carrying out important exploration work; and this has resulted in a rich harvest, including many rare specimens. Prof. $\mathrm{Hu}$ himself is attached to the Fan Memorial Institute of Biology which was established in 1928, and is wholly devoted to the taxonomic study of the flora and fauna of China. The botanical section carries out exploration in Yunnan, during which many new genera have been discovered. Monographic studies of ferns and flowering plant families are also being made, which are published in the bulletins of the Institute. In connexion with systematic botany in China, three botanic gardens have been established. The other branches of botany are still at the pioneer stage. Valuable work is being done on freshwater and marine algæ, mycology and morphology. We would, however, like to see further recruits to the small band of Chinese botanists studying plant physiology, ecology and genetics, in order that the whole subject may become more balanced, since all the subdivisions of the science are so interrelated that satisfactory progress in the whole is not easy without equal progress in each part.

\section{Plastics for Use in Electrical Engineering}

In a recent paper (J. Inst. Elec. Eng., Oct.), A. R. Dunton gives an account of recent advances in the technique of producing plastics. This word is now used for deseribing 'moulded compounds' which produce intricately shaped articles in a suitably constructed mould under the influence of heat and pressure. The accuracy obtainable by this method has aroused great interest in both mechanical and electrical engineers. There are many fabricated articles still being sold which could be replaced conveniently and economically by suitable mouldings. In Germany, many plastics are employed, and the technical specifications made ensure that they are suitable for the purpose for which they are to be used. The articles supplied are stamped with an identification mark and the maker's number. The national laboratory in Berlin has the right to take samples at any time without warning, and if the test results are not satisfactory, the maker's name is deleted from the approved list published periodically by the laboratory. The British Standard Specification was published by the B.S.I. in 1933; but unfortunately it makes no attempt to define the characteristics of arc-resisting or high-temperature materials. The performance of nearly all plastics is coupled in practice with high temperatures. A method of making rapid tests advocated by Prof. Marten of Berlin is described. It determines without difficulty the softening point of plastics. In a paper in the same issue by A. Caress, an attempt is made to classify typical plastics into those for 'hot service' and those for use at moderate temperatures. The author says that if the electrical industry will specify clearly what it requires, the plastics industry will rapidly develop suitable materials. He states that there is a very large range of new plastic materials to be discovered and examined.

\section{Sterilized Catgut for Surgical Use}

IN a Circular (No. 1563. Price $\mathrm{l} d$. net) and accompanying Memorandum (Memo. 199. Med. Price 2d. net. London : H.M. Stationery Office) issued to county, and county borough, councils, the Minister of Health directs attention to the responsibility and risk attached to the use of imperfectly sterilized, or unsterile, catgut for surgical purposes. Several groups of cases of tetanus infection have recently occurred following surgical operations in which catgut had been employed, in some of which the infection was definitely traced to the catgut. Under the Therapeutic Substances Act, 1925, and Regulations, 1931, the manufacture for sale and the importation of sterilized surgical ligatures and sutures is prohibited except under licence from the Minister of Health, and the granting of such licence is conditional upon routine testing of samples of the product for sterility, and upon control and inspection of the process of manufacture. When 'sterilized surgical catgut' is employed, the patient may be regarded as adequately safeguarded from tetanus infection, but in many hospitals 'raw' unsterile catgut is bought for use. Such catgut is not controlled under the Therapeutic Substances Act, and is 'sterilized' in the hospital itself by a process which may or may not be satisfactory. The Memorandum describes the method of preparation and of sterilization of catgut. Respecting the sterilization process, heat is sometimes employed, but needs great care, and an aqueous solution of iodine, with or without preliminary treatment with hydrogen peroxide, is efficient and widely used. Most other sterilizing agents are inefficient, or damage the gut.

\section{Yale University Publications in Anthropology}

THe second issue of collected papers in anthropology, published by Yale University (London: Oxford University Press. 11s. 6d. net) under the editorship of Dr. E. Sapir and Dr. Leslie Spier, contains six papers, of which five deal with various aspects of the ethnography of North America. Students of primitive music will welcome an attempt to produce order in a subject to which no little attention has been given in the field, but to which comparative study has still to be applied systematically. This is a regional survey of the music and musical instruments of the indigenous inhabitants of North America by Helen H. Roberts. A contribution by Mr. William Morgan on "Human Wolves among the Navahos" will be found of considerable interest to students of European witcheraft and demonology. Not only do the Navaho beliefs relating to the werwolf bear a strong resemblance to certain of the European beliefs, but also the all-pervasive Navaho belief in witchcraft suggests something of the atmosphere in which the European witchcraft superstition and consequent persecutions became rife. Mr. George P. Murdock studies "Rank and Potlatch among the Haida", providing something of a rational setting for a custom which, as usually described, is beyond the range of normal reasoning, and thereby affording a valuable object lesson for the student of social 